\title{
Clinical Significance of the Neutrophil-to-Lymphocyte Ratio in Endocrine Therapy for Stage IV Breast Cancer
}

\author{
NOZOMI IIMORI ${ }^{1}$, SHINICHIRO KASHIWAGI ${ }^{1}$, YUKA ASANO ${ }^{1}$, WATARU GOTO ${ }^{1}$, KOJI TAKADA ${ }^{1}$, \\ KATSUYUKI TAKAHASHI ${ }^{2}$, TAKAHARU HATANO ${ }^{3}$, TSUTOMU TAKASHIMA ${ }^{1}$, SHUHEI TOMITA ${ }^{2}$, \\ HISASHI MOTOMURA ${ }^{3}$, KOSEI HIRAKAWA ${ }^{1}$ and MASAICHI OHIRA ${ }^{1}$ \\ Departments of ${ }^{1}$ Surgical Oncology, ${ }^{2}$ Pharmacology, and ${ }^{3}$ Plastic and Reconstructive Surgery, \\ Osaka City University Graduate School of Medicine, Osaka, Japan
}

\begin{abstract}
Background: Studies have found that patients with cancer exhibit abnormal leukocyte fractions, such as elevated neutrophil count and diminished lymphocyte count, and that the neutrophil-to-lymphocyte ratio (NLR) provides a surrogate marker for prognosis and response to treatment of patients after radical surgery for several different types of cancer. However, few reports have addressed the association between the NLR and response to endocrine therapy. In this study, we carried out a clinical investigation to confirm whether or not the NLR predicted the response to endocrine therapy of stage IV breast cancer. Patients and Methods: The study subjects were 34 patients who underwent endocrine therapy as initial drug therapy for stage IV breast cancer. The correlation between NLR and prognosis, including the efficacy of endocrine therapy, was evaluated retrospectively. Results: Among the 34 patients, the NLR was high in 10 (29.4\%) and low in 24 (70.6\%). In analysis of outcomes, the group with low NLR had a significant prolongation of progression-free survival ( $p=0.003)$, time to treatment failure $(p=0.031)$, and overall survival $(p=0.013)$ compared to the group with high NLR. Univariate analysis of progression-free survival found that responding to treatment [hazard ratio $(H R)=4.310, p=0.004]$ and low NLR $(H R=3.940, p=0.016)$ were factors associated with a favorable prognosis. Multivariate analysis also showed that responding to treatment $(H R=4.329, p=0.006)$ and low NLR $(H R=3.930$, $p=0.008)$ were independent factors associated with a
\end{abstract}

This article is freely accessible online.

Correspondence to: Shinichiro Kashiwagi, MD, Ph.D., Osaka City University Graduate School of Medicine, 1-4-3 Asahi-machi, Abeno-ku, Osaka 545-8585, Japan. Tel: +81 666453838, Fax: +81 666466450, e-mail: spqv9ke9@view.ocn.ne.jp

Key Words: Neutrophil-to-lymphocyte ratio, endocrine therapy, stage IV, breast cancer, predictive marker. favorable prognosis. Conclusion: Our results suggested that the NLR may represent a predictive marker for response to endocrine therapy in stage IV breast cancer.

In the clinical management of breast cancer, some patients will already be at stage IV, with distant metastasis already present at the time of initial examination. Although the prognosis for breast cancer with distant metastasis is poor, recent advances in multimodal therapies now offer promise for improving this prognosis (1). Nevertheless, once breast cancer has progressed from the primary tumor to beyond regional lymph nodes, complete recovery is difficult. The objective of treatment then shifts from recovery to palliative care, with the goals of controlling symptoms, improving quality of life (QOL), and prolonging overall survival (OS). In particular, in the treatment of conditions that are non-lifethreatening, it is important to select therapies that maintain QOL. Endocrine therapy causes milder adverse events compared to chemotherapy, and is therefore often chosen in cases of hormone receptor-positive breast cancer (HRBC) for this reason (Hortobagyi's algorithm) (2). Some patients who are positive for hormone receptor expression nevertheless exhibit resistance to hormone therapy, with resistance to first-line therapy being termed 'de novo' endocrine resistance and resistance to second-line or subsequent therapy as 'acquired' endocrine resistance. If it were possible to predict de novo endocrine resistance before the start of treatment, this would greatly contribute to the choice of treatment for stage IV breast cancer. Reported markers of response to endocrine therapy include the preoperative endocrine prognostic index and Ki67 level for preoperative endocrine therapy for early-stage breast cancer $(3,4)$. However, no predictor of the response of stage IV HRBC to endocrine therapy has yet been identified.

Studies have found that patients with cancer exhibit abnormal leukocyte fractions, such as elevated neutrophil count and diminished lymphocyte count, and that the neutrophil-to-lymphocyte ratio (NLR) provides a surrogate 
in vivo $32: 669-675(2018)$

Table I. Demographical data of 34 patients treated with endocrine therapy for stage IV breast cancer.

\begin{tabular}{lcc}
\hline & Parameter (n=34) & Value \\
\hline Age, years & Median (range) & $63(44-88)$ \\
Menopause, $\mathrm{n}(\%)$ & Post-/pre- & $28(82.4 \%) / 6(17.6 \%)$ \\
Metastasis, $\mathrm{n}(\%)$ & Bone or soft-tissue/visceral & $17(50.0 \%) / 17(50.0 \%)$ \\
ER or PgR, $\mathrm{n}(\%)$ & Strongly positive/weakly positive & $28(82.4 \%) / 6(17.6 \%)$ \\
HER2, $\mathrm{n}(\%)$ & Negative/positive & $30(88.2 \%) / 4(11.8 \%)$ \\
Ki67, $\mathrm{n}(\%)$ & $\leq 14 \% />14 \%$ & $27(79.4 \%) / 7(20.6 \%)$ \\
Treatment, $\mathrm{n}(\%)$ & Letrozole/anastrozole/tamoxifen*/exemestane & $20(58.8 \%) / 7(20.6 \%) / 6(17.7 \%) / 1(2.9 \%)$ \\
Clinical response, $\mathrm{n}(\%)$ & $\mathrm{CR} / \mathrm{PR} / \mathrm{SD} \geq 24$ weeks/SD<24 weeks/PD & $0(0.0 \%) / 26(76.5 \%) / 4(11.7 \%) / 2(5.9 \%) / 2(5.9 \%)$ \\
Clinical response, $\mathrm{n}(\%)$ & ORR/CBR/DCR & $26(76.5 \%) / 30(88.2 \%) / 32(94.1 \%)$ \\
NLR & High/Low & $10(29.4 \%) / 24(70.6 \%)$ \\
\hline
\end{tabular}

ER, Estrogen receptor; PgR, progesterone receptor; HER2, human epidermal growth factor receptor 2; CR, complete response; PR, partial response; $\mathrm{SD}$, stable disease; PD, progressive disease; ORR, objective response rate; CBR, clinical benefit response; DCR, disease control rate. neutrophilto-lymphocyte ratio (NLR). *With/without LHRH agonist.

marker for the prognosis and response to treatment of patients after radical surgery for several different types of cancer (5-8). Neutrophils act to encourage the proliferation of tumor cells and to promote angiogenesis and distant metastasis, while lymphocytes are known to be responsible for the immune reaction to tumors. The NLR provides an index of their correlation, and patients with a high NLR have been shown to have a worse prognosis than those with a low NLR, and to be resistant to chemotherapy $(7,9,10)$. However, few reports have addressed the association between the NLR and response to endocrine therapy. We therefore hypothesized that the NLR may provide a predictive marker for response to endocrine therapy. In this study, we carried out a clinical investigation to confirm whether or not the NLR predicted the response to endocrine therapy of stage IV breast cancer.

\section{Materials and Methods}

Patient background. The study subjects were 34 patients who underwent endocrine therapy as initial drug therapy for stage IV breast cancer at our hospital between June 2004 and December 2013. The median follow-up time was 155 weeks ( range $=13-553$ weeks). The overall response rate (ORR), clinical benefit rate (CBR), disease control rate (DCR), OS, time to treatment failure (TTF) and progression-free survival (PFS) were calculated regarding the efficacy of this regimen. The ORR was calculated as the sum of patients with complete (CR) or partial (PR) response. The CBR was calculated as the sum of CR, PR and stable disease (SD) (for $>24$ weeks) divided by the total number of patients. The DCR was calculated as the sum of CR, PR and SD (other) divided bythetotal number of patients. The OS was evaluated daily and was calculated as the time from the start of treatment to the patient's death. The TTF was evaluated daily and was calculated as the time from the start of treatment to discontinuation of treatment for any reason, including disease aggravation, adverse events, or death. The PFS was evaluated daily and was calculated as the time from the start of treatment to either confirmation of progressive disease or death, whichever occurred first. Additionally, tumor stage and $\mathrm{T}$ and $\mathrm{N}$ factors were stratified based on the Seventh Edition of the Union for International Cancer Control (UICC) TNM Classification of Malignant Tumors (11). Breast cancer was confirmed histologically by core needle biopsy and staged by systemic imaging studies using computed tomography, ultrasonography, and bone scintigraphy. Breast cancer was classified into subtypes according to the immunohistochemical expression of estrogen receptor (ER), progesterone receptor (PR), epidermal growth factor receptor 2 (HER2), and Ki67. Based on their immunohistochemical expression, the tumours were categorized into the immunophenotypes: luminal A (ER-positive and/or PgR-positive, HER2-negative, Ki67-low), luminal B (ER-positive and/or PgR-positive, HER2-positive: luminal HER2; ER-positive and/or PgR-positive, HER2-negative, Ki67-high), HER2-enriched (ER-negative, PgR-negative, and HER2-positive), and TNBC (negative for ER, PgR and HER2) (12). In this study, luminal A and luminal B were considered as HRBC.

The endocrine therapy was administered on an outpatient basis in all cases. This protocol was repeated until progressive disease (PD) was detected or a severe adverse event requiring the discontinuation of the scheduled endocrine therapy was noted. Therapeutic antitumor effects were assessed according to the Response Evaluation Criteria in Solid Tumors (RECIST) criteria (13). All clinical evaluations in this study were performed by image assessment. TTF was evaluated on a daily basis and was set as the period from the date of treatment commencement to cancellation for any reason, including disease aggravation, treatment toxicity and death. OS was evaluated on a daily basis and was set as the period from the date of treatment commencement to death. PFS was evaluated on a daily basis and was set as the period from the date of treatment commencement to the earlier of the date of death or confirmation of PD.

Ethics statement. This study was conducted at Osaka City University Graduate School of Medicine, Osaka, Japan, according to the Reporting Recommendations for Tumour Marker Prognostic Studies (REMARK) guidelines and a retrospectively written, research, pathological evaluation, and statistical plan. Written, informed consent was obtained from all patients. This research 
conformed to the provisions of the Declaration of Helsinki in 2013. The study protocol was approved by the Ethics Committee of Osaka City University (\#926).

Blood sample analysis. Peripheral blood was obtained at the time of diagnosis, before treatment. The numbers of white blood cells were determined using a hemocytometer. The percentages of different types of cells were determined using a Coulter LH 750 Hematology Analyzer (Beckman Coulter, Brea, CA, USA). NLR was calculated from the preoperative blood sample by dividing the absolute neutrophil count by the absolute lymphocyte count. Based on previous studies, an NLR value of 3.0 was used as the cutoff value to discriminate between high-NLR $(\geq 3.0)$ and low-NLR $(<3.0)(10,14,15)$

Statistical analysis. Statistical analysis was performed using the SPSS version 19.0 statistical software package (IBM, Armonk, NY, USA). The associations between NLR and clinicopathological variables, and the significance of different prognostic markers were analyzed using the chi-square test (or Fisher's exact test when necessary). The Kaplan-Meier method was used to estimate the values of OS, TTF and PFS. The OS, TTF and PFS values were compared using the log-rank test. The Cox proportional hazards model was used to compute univariate and multivariate hazards ratios (HR) for the study parameters with $95 \%$ confidence interval (CI), and was used in a backward stepwise method for variable selection in multivariate analyses. A $p$-value of less than 0.05 was considered significant. Cutoff values for different biomarkers included in this study were chosen before statistical analysis $(10,14,15)$.

\section{Results}

Endocrine therapy in stage IV breast cancer. Table I shows the background characteristics of 34 patients who underwent endocrine therapy as the initial drug therapy for stage IV breast cancer (Table I). All patients were women, with a median age of 63 years (range 44 to 88 years); bone or soft tissue was the site of metastasis in 17 patients $(50.0 \%)$, and visceral metastasis was present in 17 patients (50.0\%). The median PFS was 75 weeks (Figure 1A), median TTF was 65 weeks (Figure 1B), and median OS was 379 weeks (Figure 1C).

Prediction of response to treatment using the NLR. Among all 34 patients, the NLR was high in $10(29.4 \%)$ and low in 24 (70.6\%) patients. Investigation of the clinical pathological features of patients showed no significant differences between the high and low NLR groups (Table II). In analysis of outcomes, the low NLR group had significant prolongation of PFS ( $p=0.003, \log$-rank) (Figure 2A), TTF ( $p=0.031, \log$ rank) (Figure $2 \mathrm{~B})$, and OS ( $p=0.013$, log-rank) (Figure $2 \mathrm{C}$ ) compared to the high NLR group. Univariate analysis of PFS found that responding to treatment $(\mathrm{HR}=4.310, p=0.004)$ and low NLR $(\mathrm{HR}=3.940, p=0.016)$ were factors associated with a favorable prognosis (Table III) (Figure 3). Multivariate analysis confirmed that responding to treatment $(\mathrm{HR}=4.329$,
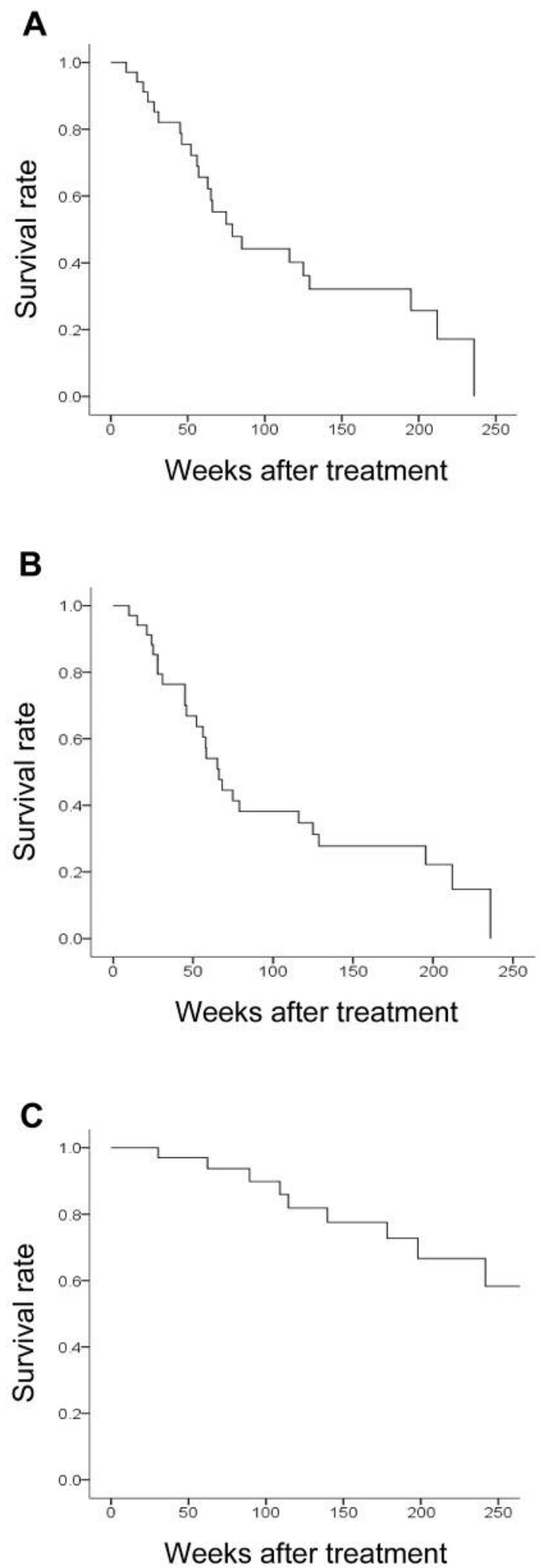

Figure 1. Clinical effects of endocrine therapy for stage IV breast cancer. Kaplan-Meier curves for progression-free survival (PFS) (A) (median=75 weeks), time to treatment failure $(T T F)(B)($ median $=65$ weeks), and overall survival (OS) (C) (median=379 weeks). 
Table II. Correlation between clinicopathological features and neutrophil-to-lymphocyte ratio (NLR) in 34 patients with stage IV breast cancer.

\begin{tabular}{|c|c|c|c|}
\hline \multirow[t]{2}{*}{ Parameter } & \multicolumn{2}{|c|}{ NLR, n (\%) } & \multirow[t]{2}{*}{$p$-Value } \\
\hline & High $(n=10)$ & Low $(n=24)$ & \\
\hline \multicolumn{4}{|l|}{ Age at operation } \\
\hline$\leq 64$ Years & $6(60.0 \%)$ & $13(54.2 \%)$ & \\
\hline$>64$ Years & $4(40.0 \%)$ & $11(45.8 \%)$ & 0.529 \\
\hline \multicolumn{4}{|l|}{ Menopause } \\
\hline Pre-menopausal & $0(0.0 \%)$ & $6(25.0 \%)$ & \\
\hline Post-menopausal & $10(100.0 \%)$ & $18(75.0 \%)$ & 0.100 \\
\hline \multicolumn{4}{|l|}{ Metastasis } \\
\hline Bone or soft-tissue & $6(60.0 \%)$ & $11(45.8 \%)$ & \\
\hline Visceral & $4(40.0 \%)$ & $13(54.2 \%)$ & 0.354 \\
\hline \multicolumn{4}{|l|}{ ER or $\mathrm{PgR}$} \\
\hline Strongly positive & $7(70.0 \%)$ & $21(87.5 \%)$ & \\
\hline Weakly positive & $3(30.0 \%)$ & $3(12.5 \%)$ & 0.228 \\
\hline \multicolumn{4}{|l|}{ HER2 } \\
\hline Negative & $9(90.0 \%)$ & $21(87.5 \%)$ & \\
\hline Positive & $1(10.0 \%)$ & $3(12.5 \%)$ & 0.666 \\
\hline \multicolumn{4}{|l|}{ Ki67 index } \\
\hline$\leq 14 \%$ & $10(100.0 \%)$ & $17(70.8 \%)$ & \\
\hline$>14 \%$ & $0(0.0 \%)$ & $7(29.2 \%)$ & 0.064 \\
\hline \multicolumn{4}{|l|}{ Objective response } \\
\hline Yes & $6(60.0 \%)$ & $20(83.3 \%)$ & \\
\hline No & $4(40.0 \%)$ & $4(16.7 \%)$ & 0.154 \\
\hline
\end{tabular}

ER, Estrogen receptor; PgR, progesterone receptor; HER2, human epidermal growth factor receptor 2 .

$p=0.006)$ and low NLR $(\mathrm{HR}=3.930, p=0.008)$ were independent factors associated with a favorable prognosis.

\section{Discussion}

The TNM classification of tumor factors has conventionally been used as an indicator of cancer prognosis, but cancers at the same stage of progression vary in their prognosis, and host factors such as inflammatory reaction, nutritional status, and immune environment have been attracting attention as new indices (16-18). These indices of inflammation are calculated based on leukocytes, neutrophils, lymphocytes, platelets, C-reactive protein, albumin, and other factors contained in blood, and are therefore easy to measure $(19,20)$. Combinations of these factors, such as the NLR, the lymphocyte-to-monocyte ratio, the platelet-to-lymphocyte ratio, and the Glasgow prognostic score have been reported as useful predictive markers for cancer prognosis $(5,21-23)$. In the breast cancer field, it was recently reported that immune reactions are implicated in response to treatment and play an important role in prognosis (24). The host immune response to cancer is now believed to affect not only the results of immunotherapy, but
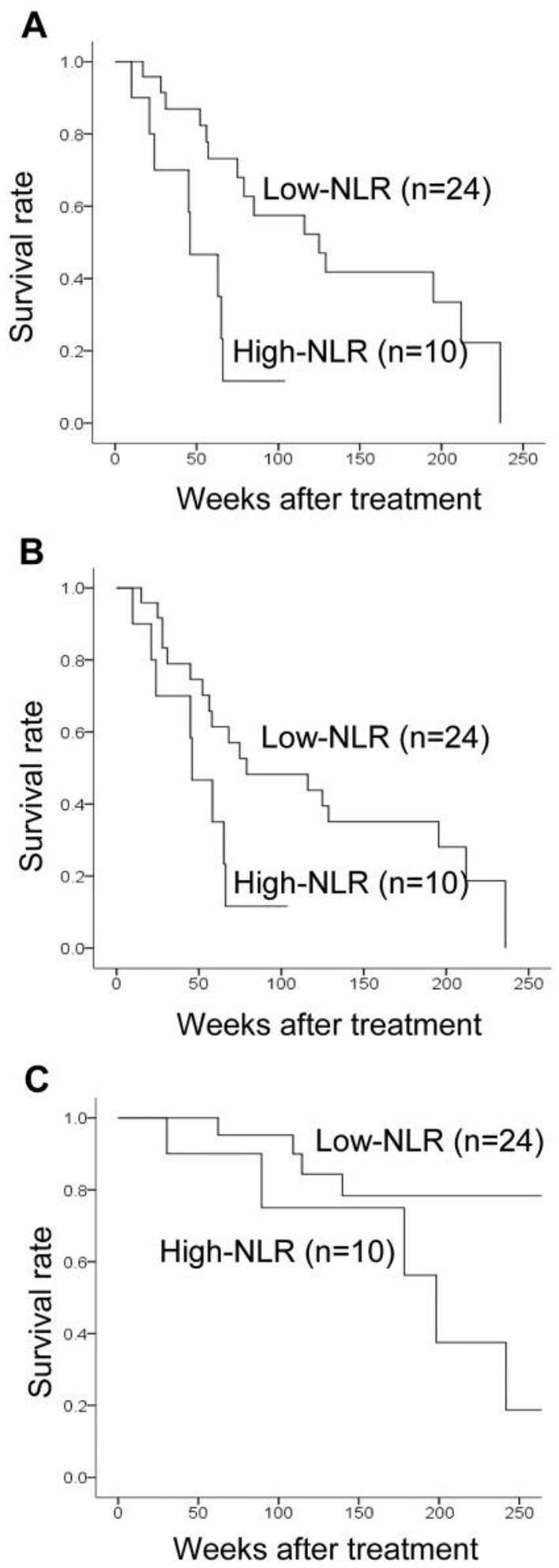

Figure 2. Kaplan-Meier curves for progression-free survival (PFS) (A), time to treatment failure $(T T F)(B)$, and overall survival $(O S)(C)$ of patients with stage IV breast cancer according to neutrophil-to-lymphocyte ratio (NLR). In analysis of outcomes, the group with a low NLR had significant prolongation of PFS (log-rank $p=0.003)$, TTF (log-rank $p=0.031$, and OS (log-rank $p=0.013)$ compared to the group with high NLR. 


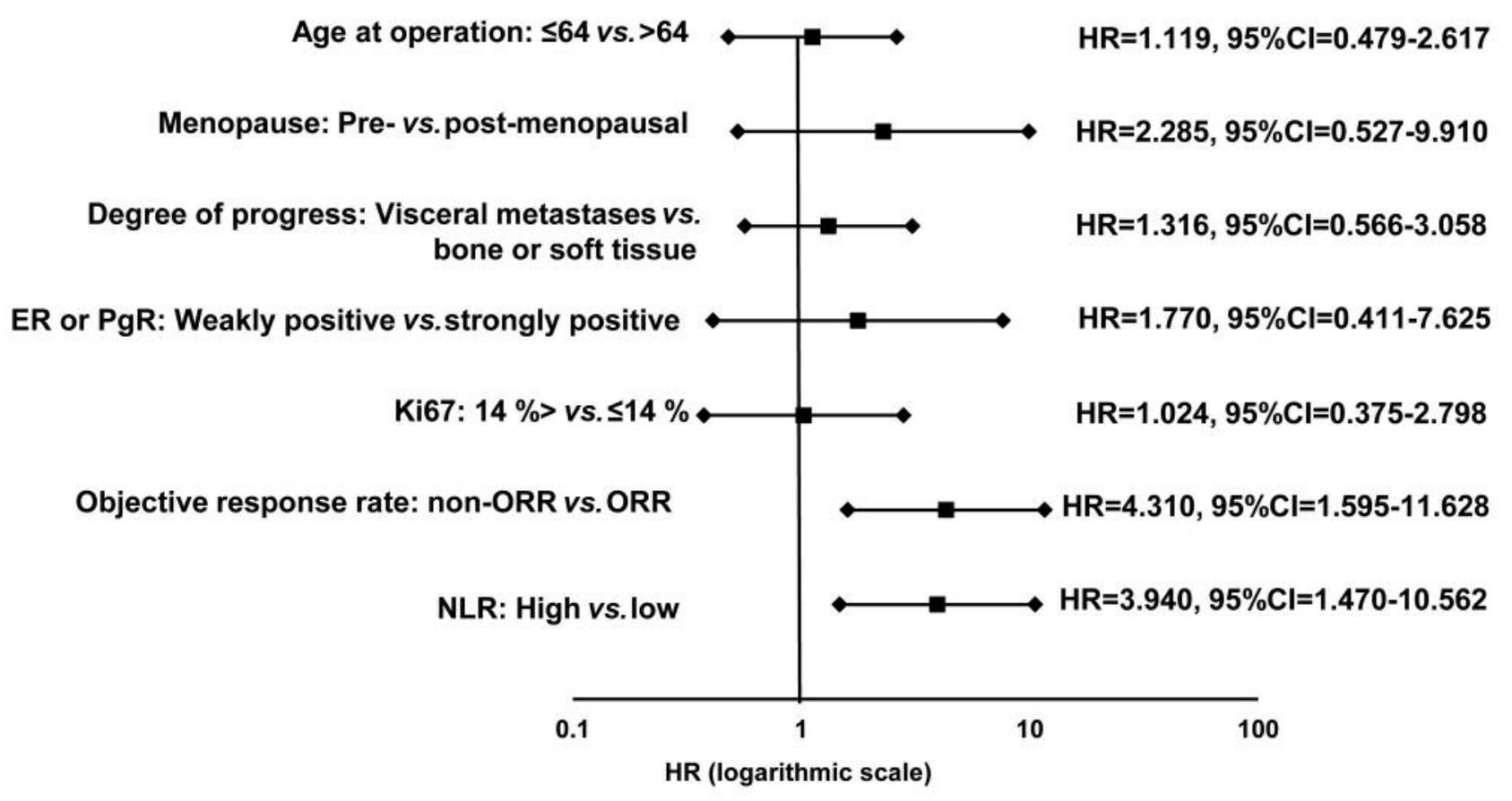

Figure 3. Forest plots of the results of progression-free survival analysis. Univariate analysis of progression-free survival found that responding to treatment hazard ratio=4.310) and low neutrophil-to-lymphocyte ratio $(N L R)$ (hazard ratio=3.940, $p=0.016)$ were factors associated with a favorable prognosis.

Table III. Univariate and multivariate analysis with respect to progression-free survival in 34 patients with stage IV breast cancer.

\begin{tabular}{|c|c|c|c|c|c|c|c|}
\hline \multirow[b]{2}{*}{ Parameter } & & \multicolumn{3}{|c|}{ Univariate analysis } & \multicolumn{3}{|c|}{ Multivariate analysis } \\
\hline & & Hazard ratio & $95 \% \mathrm{CI}$ & $p$-Value & Hazard ratio & $95 \% \mathrm{CI}$ & $p$-Value \\
\hline Age & $\leq 64 v s .>64$ Years & 1.119 & $0.479-2.617$ & 0.795 & & & \\
\hline Menopause & Pre- vs. Post-menopausal & 2.285 & $0.527-9.910$ & 0.270 & & & \\
\hline Metastasis & Visceral $v s$. bone or soft-tissue & 1.316 & $0.566-3.058$ & 0.523 & & & \\
\hline ER or PgR & Weakly positive $v s$. strongly positive & 1.770 & $0.411-7.625$ & 0.443 & & & \\
\hline Ki67 index & $>14 \%$ vs. $\leq 14 \%$ & 1.024 & $0.375-2.798$ & 0.963 & & & \\
\hline Objective response & No $v s$. yes & 4.310 & $1.595-11.628$ & 0.004 & 4.329 & $1.534-12.195$ & 0.006 \\
\hline NLR & High vs. Low & 3.940 & $1.470-10.562$ & 0.016 & 3.930 & $1.424-10.845$ & 0.008 \\
\hline
\end{tabular}

CI, Confidence interval; ER, estrogen receptor; PgR, progesterone receptor; ORR, overall response rate; NLR, neutrophil-to-lymphocyte ratio.

also the response to conventional anticancer therapies such as chemotherapy, as well as prognosis $(25,26)$. However, few studies have addressed the association between these indices for evaluating systemic inflammatory response and endocrine therapy.

In addition to estrogen, the endocrine receptors that play an important role in the development and progression of breast cancer are also activated via multiple signal cascades, such as pathways mediated by phosphorylation by growth factors (non-genomic action), and their regulation is dependent on the immune microenvironment surrounding cancer cells (27). For this reason, regulating and improving the immune response to cancer may also be key in endocrine therapy that has been shown to have an antitumor effect by blocking the action of estrogen or suppressing its production. Studies have also found a correlation between stage of progression and immune activity in the immune response to cancer. Stage IV breast cancer, which was the subject of this study, is thus a state of high immune activity, suggesting that the NLR and other indices of inflammation may provide useful biomarkers of its response to endocrine therapy. 
In this study, patients with a low NLR exhibited greater sensitivity to endocrine therapy compared with those with a high NLR. A possible mechanism for this correlation between the NLR and endocrine sensitivity is as follows. The host's non-specific systemic inflammatory response to the tumor results in an increase in neutrophils and a relative decrease in lymphocytes, which increases the NLR. Neutrophils release chemokines and other substances that promote angiogenesis, thereby increasing tumor growth, whereas lymphocytes are involved in antitumor immunity and thus act to inhibit tumors. A rise in the NLR is therefore implicated in tumor growth and progression and indicates a poor prognosis. In states of high immune activity such as stage IV breast cancer, the NLR becomes relatively lower. The use of endocrine therapy for patients with a low NLR will further activate the immune response, thus enhancing its antitumor effect.

Furthermore, in chemotherapy and radiotherapy, immunogenic cell death is induced by treatment (28-30). Cancer cells that have undergone immunogenic cell death induce the maturation of dendritic cells (DCs) via the action of toll-like receptor expressed on the surface of DCs, whose activation is mediated by high-mobility group box 1, thereby promoting antigen presentation and T-cell activation (31). Anticancer treatments thus have a profound effect on the body's immune response, and the immune response may also be activated by a similar mechanism in endocrine therapy.

In this study, we evaluated the NLR in the peripheral blood of patients with stage IV breast cancer. As it uses blood sampled prior to treatment, it has the advantages of simplicity and imposing little strain on patients. However, this study had the limitation of being a retrospective study of a small number of patients. It is to be hoped that international phase III clinical trials of neoadjuvant endocrine therapy will also investigate the value of the NLR in predicting response to treatment $(4,32)$.

Our results suggested that the NLR may act as a predictive marker for response to endocrine therapy in stage IV breast cancer.

\section{Conflicts of Interest}

The Authors have no conflicts of interest to disclose in regard to this study.

\section{Sources of Support}

This study was funded by grants from the Japan Society for the Promotion of Science (KAKENHI, Nos. 25461992, 26461957, and 17K10559) to Shinichiro Kashiwagi.

\section{Acknowledgements}

The Authors thank Yayoi Matsukiyo and Tomomi Okawa (Department of Surgical Oncology, Osaka City University Graduate School of Medicine) for helpful advice regarding data management.

\section{References}

1 Andre F, Slimane K, Bachelot T, Dunant A, Namer M, Barrelier A, Kabbaj O, Spano JP, Marsiglia H, Rouzier R, Delaloge S and Spielmann M: Breast cancer with synchronous metastases: trends in survival during a 14-year period. J Clin Oncol 22: 3302-3308, 2004.

2 Hortobagyi GN: Treatment of breast cancer. N Engl J Med 339: 974-984, 1998.

3 Ellis MJ, Tao Y, Luo J, A'Hern R, Evans DB, Bhatnagar AS, Chaudri Ross HA, von Kameke A, Miller WR, Smith I, Eiermann $\mathrm{W}$ and Dowsett M: Outcome prediction for estrogen receptorpositive breast cancer based on postneoadjuvant endocrine therapy tumor characteristics. J Natl Cancer Inst 100: 1380-1388, 2008.

4 Ellis MJ, Suman VJ, Hoog J, Lin L, Snider J, Prat A, Parker JS, Luo J, DeSchryver K, Allred DC, Esserman LJ, Unzeitig GW, Margenthaler J, Babiera GV, Marcom PK, Guenther JM, Watson MA, Leitch M, Hunt K and Olson JA: Randomized phase II neoadjuvant comparison between letrozole, anastrozole and exemestane for postmenopausal women with estrogen receptorrich stage 2 to 3 breast cancer: clinical and biomarker outcomes and predictive value of the baseline PAM50-based intrinsic subtype--ACOSOG Z1031. J Clin Oncol 29: 2342-2349, 2011.

5 Malietzis G, Giacometti M, Kennedy RH, Athanasiou T, Aziz O and Jenkins JT: The emerging role of neutrophil to lymphocyte ratio in determining colorectal cancer treatment outcomes: a systematic review and meta-analysis. Ann Surg Oncol 21: 39383946, 2014

6 Templeton AJ, McNamara MG, Seruga B, Vera-Badillo FE, Aneja P, Ocana A, Leibowitz-Amit R, Sonpavde G, Knox JJ, Tran B, Tannock IF and Amir E: Prognostic role of neutrophilto-lymphocyte ratio in solid tumors: a systematic review and meta-analysis. J Natl Cancer Inst 106: dju124, 2014.

7 Luo G, Guo M, Liu Z, Xiao Z, Jin K, Long J, Liu L, Liu C, Xu J, Ni Q and Yu X: Blood neutrophil-lymphocyte ratio predicts survival in patients with advanced pancreatic cancer treated with chemotherapy. Ann Surg Oncol 22: 670-676, 2015.

8 Shibutani M, Maeda K, Nagahara H, Noda E, Ohtani H, Nishiguchi Y and Hirakawa K: A high preoperative neutrophilto-lymphocyte ratio is associated with poor survival in patients with colorectal cancer. Anticancer Res 33: 3291-3294, 2013.

9 Rossi L, Santoni M, Crabb SJ, Scarpi E, Burattini L, Chau C, Bianchi E, Savini A, Burgio SL, Conti A, Conteduca V, Cascinu $\mathrm{S}$ and De Giorgi U: High neutrophil-to-lymphocyte ratio persistent during first-line chemotherapy predicts poor clinical outcome in patients with advanced urothelial cancer. Ann Surg Oncol 22: 1377-1384, 2015.

10 Asano Y, Kashiwagi S, Onoda N, Noda S, Kawajiri H, Takashima T, Ohsawa M, Kitagawa $\mathrm{S}$ and Hirakawa K: Predictive Value of neutrophil/lymphocyte ratio for efficacy of preoperative chemotherapy in triple-negative breast cancer. Ann Surg Oncol 23: 1104-1110, 2016.

11 Greene FL and Sobin LH: A worldwide approach to the TNM staging system: collaborative efforts of the AJCC and UICC. J Surg Oncol 99: 269-272, 2009.

12 Goldhirsch A, Wood WC, Coates AS, Gelber RD, Thurlimann B, Senn HJ and Panel m: Strategies for subtypes - dealing with the diversity of breast cancer: highlights of the St. Gallen International Expert Consensus on the Primary Therapy of Early Breast Cancer 2011. Ann Oncol 22: 1736-1747, 2011. 
13 Eisenhauer EA, Therasse P, Bogaerts J, Schwartz LH, Sargent D, Ford R, Dancey J, Arbuck S, Gwyther S, Mooney M, Rubinstein L, Shankar L, Dodd L, Kaplan R, Lacombe D and Verweij J: New response evaluation criteria in solid tumours: revised RECIST guideline (version 1.1). Eur J Cancer 45: 228247, 2009.

14 Perez DR, Baser RE, Cavnar MJ, Balachandran VP, Antonescu CR, Tap WD, Strong VE, Brennan MF, Coit DG, Singer S and Dematteo RP: Blood neutrophil-to-lymphocyte ratio is prognostic in gastrointestinal stromal tumor. Ann Surg Oncol 20: 593-599, 2013.

15 Noh H, Eomm M and Han A: Usefulness of pretreatment neutrophil to lymphocyte ratio in predicting disease-specific survival in breast cancer patients. J Breast Cancer 16: 55-59, 2013.

$16 \mathrm{Lu} \mathrm{H}$, Ouyang $\mathrm{W}$ and Huang C: Inflammation, a key event in cancer development. Mol Cancer Res 4: 221-233, 2006.

17 Toyokawa T, Kubo N, Tamura T, Sakurai K, Amano R, Tanaka $\mathrm{H}$, Muguruma K, Yashiro M, Hirakawa K and Ohira M: The pretreatment Controlling Nutritional Status (CONUT) score is an independent prognostic factor in patients with resectable thoracic esophageal squamous cell carcinoma: results from a retrospective study. BMC Cancer 16: 722, 2016.

18 Iyengar NM, Hudis CA and Dannenberg AJ: Obesity and cancer: local and systemic mechanisms. Annu Rev Med 66: 297-309, 2015.

19 Shibutani M, Maeda K, Nagahara H, Ohtani H, Sakurai K, Yamazoe A, Kimura K, Toyokawa T, Amano R, Kubo N, Tanaka H, Muguruma K, Ohira M and Hirakawa K: Significance of markers of systemic inflammation for predicting survival and chemotherapeutic outcomes and monitoring tumor progression in patients with unresectable metastatic colorectal cancer. Anticancer Res 35: 5037-5046, 2015.

20 Asano Y, Kashiwagi S, Onoda N, Noda S, Kawajiri H, Takashima T, Ohsawa M, Kitagawa S and Hirakawa K: Plateletlymphocyte ratio as a useful predictor of the therapeutic effect of neoadjuvant chemotherapy in breast cancer. PLoS One 11: e0153459, 2016.

21 Ni XJ, Zhang XL, Ou-Yang QW, Qian GW, Wang L, Chen S, Jiang YZ, Zuo WJ, Wu J, Hu X and Shao ZM: An elevated peripheral blood lymphocyte-to-monocyte ratio predicts favorable response and prognosis in locally advanced breast cancer following neoadjuvant chemotherapy. PLoS One 9: e111886, 2014.

22 Iseki Y, Shibutani M, Maeda K, Nagahara H, Tamura T, Ohira G, Yamazoe S, Kimura K, Toyokawa T, Amano R, Tanaka H, Muguruma K, Hirakawa K and Ohira M: The impact of the preoperative peripheral lymphocyte count and lymphocyte percentage in patients with colorectal cancer. Surg Today 47: $743-754,2017$.
23 Azab B, Shah N, Radbel J, Tan P, Bhatt V, Vonfrolio S, Habeshy A, Picon A and Bloom S: Pretreatment neutrophil/lymphocyte ratio is superior to platelet/lymphocyte ratio as a predictor of long-term mortality in breast cancer patients. Med Oncol 30: 432, 2013.

24 Savas P, Salgado R, Denkert C, Sotiriou C, Darcy PK, Smyth MJ and Loi S: Clinical relevance of host immunity in breast cancer: from TILs to the clinic. Nat Rev Clin Oncol 13: 228$241,2016$.

25 Dougan M and Dranoff G: Immune therapy for cancer. Annu Rev Immunol 27: 83-117, 2009.

26 Zitvogel L, Kepp $\mathrm{O}$ and Kroemer G: Immune parameters affecting the efficacy of chemotherapeutic regimens. Nat Rev Clin Oncol 8: 151-160, 2011.

27 Omoto Y, Eguchi H, Yamamoto-Yamaguchi Y and Hayashi S: Estrogen receptor (ER) beta1 and ERbetacx/beta2 inhibit ERalpha function differently in breast cancer cell line MCF7. Oncogene 22: 5011-5020, 2003.

28 Kroemer G, Galluzzi L, Kepp O and Zitvogel L: Immunogenic cell death in cancer therapy. Annu Rev Immunol 31: 51-72, 2013.

29 Kono K, Mimura K and Kiessling R: Immunogenic tumor cell death induced by chemoradiotherapy: molecular mechanisms and a clinical translation. Cell Death Dis 4: e688, 2013.

30 Tesniere A, Panaretakis T, Kepp O, Apetoh L, Ghiringhelli F, Zitvogel L and Kroemer G: Molecular characteristics of immunogenic cancer cell death. Cell Death Differ 15: 3-12, 2008.

31 Yamazaki T, Hannani D, Poirier-Colame V, Ladoire S, Locher C, Sistigu A, Prada N, Adjemian S, Catani JP, Freudenberg M, Galanos $\mathrm{C}$ andre F, Kroemer $\mathrm{G}$ and Zitvogel L: Defective immunogenic cell death of HMGB1-deficient tumors: compensatory therapy with TLR4 agonists. Cell Death Differ 21: 69-78, 2014.

32 Cataliotti L, Buzdar AU, Noguchi S, Bines J, Takatsuka Y, Petrakova K, Dube P and de Oliveira CT: Comparison of anastrozole versus tamoxifen as preoperative therapy in postmenopausal women with hormone receptor-positive breast cancer: the Pre-Operative "Arimidex" Compared to Tamoxifen (PROACT) trial. Cancer 106: 2095-2103, 2006.
Received January 23, 2018

Revised March 7, 2018

Accepted March 8, 2018 